\title{
Transmission of Novel Bacterial Pathogens through Pigs Transported from Myanmar to Mizoram
}

\author{
C. Lalremruata, T.K. Dutta, P. Roychoudhury, \\ Sanjeev Kumar, A. Sen, N.N. Barman², P.K. Subudhi
}

10.18805/IJAR.B-4197

\begin{abstract}
Background: Illegal migration of pigs/piglets from Myanmar to Mizoram is a common practice to meet the local demands. The migrated animals are suspected as potential carrier of various microbial pathogens. The present study was conducted on isolation, identification and molecular characterization of major bacterial pathogens (Actinobacillus pleuropneumoniae, Bordetella bronchiseptica, Haemophilus parasuis, Mycoplasma hyopneumoniae and Pasteurella multocida) in pigs illegally migrated from Myanmar to Mizoram. Methods: A total of 209 rectal swabs and 209 nasal swabs were collected from apparently healthy migrated pigs during October 2018 to April, 2019. All the samples were processed for PCR based detection of target bacterial species followed by isolation and identification by bacteriological techniques. The bacterial species were further confirmed by BD Phoenix automated bacterial identification system and selected virulence genes of the bacterial species were determined by specific PCR assay.

Result: By species specific PCR, 110 samples were found to be positive for selected bacterial species, of which 20 (9.57\%), 1 (0.478\%), $86(41.15 \%), 2(0.956 \%)$ and $1(0.478 \%)$ were A. pleuropneumoniae, B. bronchiseptica, H. parasuis, M. hyopneumoniae and $P$. multocida, respectively. A total of 52 bacterial strains were isolated and identified, of which 11, 1, 39 and 1 were $A$. pleuropneumoniae, B. bronchiseptica, H. parasuis, M. hyopneumoniae and P. multocida, respectively. Virulence genes were detected in $A$. pleuropneumoniae and $H$. parasuis isolates. Based upon the published literatures, this is the first ever report of isolation and identification of pathogenic A. pleuropneumoniae and $H$. parasuis in pigs in India.
\end{abstract}

Key words: Bacteria, Mizoram, Pigs, Transboundary.

\section{INTRODUCTION}

Animal husbandry is one of the major livelihood sources for the majority of the population in the North-East Region (NER) of India. The pigs occupy the unique position as it is considered as a taboo in the socio-cultural life of tribal people (Das and Bujarbaruah, 2005). In Mizoram, the North-eastern state of India, pig is the most preferable and important livestock and plays a major role in the livelihood of the small farmers. Due to non-availability of healthy piglets through state agencies and multiple disease outbreaks the gap between the supply and demand is wide. The piglets are being transported across the domestic and international borders into Mizoram to meet the excess demands. Due to the uncontrolled migration of young and adult pigs in the state, there is ample chance of introduction of various infections among the pig population of Mizoram and recent outbreaks of porcine reproductive and respiratory syndrome (PRRS) in 2013, 2015 and 2018 are considered as valid evidence (Rajkhowa et al., 2016; Zohlimpuia et al., 2018).

Besides the major viral pathogens, many bacterial agents including Actinobacillus pleuropneumoniae, Bordetella bronchiseptica, Haemophilus parasuis, Mycoplasma hyopneumoniae and Pasteurella multocida are recognized as major etiological agents of various porcine diseases. B. bronchiseptica and $P$. multocida are commensal microflora in the upper respiratory tract of pigs but develop progressive atrophic rhinitis in immunocompromized animals
Department of Veterinary Microbiology, College of Veterinary Sciences and Animal Husbandry, Central Agricultural University, Selesih, Aizawl-796 014, Mizoram, India.

${ }^{1}$ Division of Animal Health, ICAR-Research Complex for North Eastern Hill Region, Umium, Shillong-793 193, Meghalaya, India. ${ }^{2}$ Department of Veterinary Microbiology, Assam Agricultural University, Khanapara, Guwahati-781 022, Assam, India.

Corresponding Author: T.K. Dutta, Department of Veterinary Microbiology, College of Veterinary Sciences and Animal Husbandry, Central Agricultural University, Selesih, Aizawl-796 014, Mizoram, India. Email: tapandutta@rediffmail.com

How to cite this article: Lalremruata, C., Dutta, T.K., Roychoudhury, P., Kumar, S., Sen, A., Barman, N.N., Subudhi, P.K. (2021). Transmission of Novel Bacterial Pathogens through Pigs Transported from Myanmar to Mizoram. Indian Journal of Animal Research. DOI: 10.18805/IJAR.B-4197.

Submitted: 23-05-2020 Accepted: 24-08-2021 Online: 24-09-2021

(Donko et al., 2003). H. parasuis is the causative agent of Glässer's disease of pigs, one of the major economically important diseases in pig industry which shows fibrinous polyserositis, polyarthritis and meningitis (Ferri et al., 2000). M. hyopneumoniae is one of the primary pathogens associated with enzootic pneumonia and porcine respiratory disease complex (PRDC) in pigs (Thacker and Minion, 2012). A. pleuropneumoniae is an economically important respiratory pathogen associated with acute and often fatal 
porcine pleuropneumonia that causes great economic losses to the swine industry.

In India, diseases of pigs associated with various bacterial pathogens including Bordetella spp., Mycoplasmas and Pasteurellae are reported earlier by various workers (Kumar et al., 2014; Behera et al., 2018; Dutta et al., 2009) but no report on detection of $A$. pleuropneumoniae and $H$. parasuis are available. In addition, no scientific study has undertaken to record the bacterial pathogens carried by the pigs illegally transported from Myanmar to Mizoram. The present study was undertaken to detect and identify the five major bacterial pathogens ( $A$. pleuropneumoniae, $B$. bronchoseptica, $H$. parasuis, $M$. hyopneumoniae and P. multocida) in pigs transported from Myanmar to Mizoram. This is probably the first ever scientific evidence on transboundary transmission of bacterial pathogens through pigs between two countries.

\section{MATERIALS AND METHODS Collection of samples}

All the samples were collected from the pigs illegally transported from Myanmar to Champhai district of Mizoram during October 2018 to April, 2019. A total of 209 nasal swabs and 209 rectal swabs were collected under aseptic condition using sterile absorbent cotton swabs (HiMedia, India). All the samples were transported to the laboratory under cold chain for further processing.

\section{Preparation of samples for screening}

All the samples were inoculated in $5 \mathrm{ml}$ sterile Brain Heart Infusion (BHI) broth (HiMedia, India) and incubated at $37^{\circ} \mathrm{C}$ for 18 hours under constant shaking (120 rpm) in a shaking incubator. After overnight incubation, $1 \mathrm{ml}$ of bacterial culture was transferred to a microcentrifuge tube (Eppendorf, Germany) and centrifuged at 8,000 rpm for 10 minutes at $4^{\circ} \mathrm{C}$. The cell pellet was washed three times in sterile normal saline solution $(0.85 \%)$ and finally resuspended in $300 \mu \mathrm{l}$ of nuclease-free sterile distilled water. The cell suspension was boiled in a water bath $\left(100^{\circ} \mathrm{C}\right)$ for 5 minutes followed by snap chilling at $-20^{\circ} \mathrm{C}$. The cellular debris was sedimented by centrifugation at 8,000 rpm for 5 minutes. The supernatant was used as the template for PCR assay. The left over $(4 \mathrm{ml})$ bacterial culture was stored at $4^{\circ} \mathrm{C}$ for further use.

\section{PCR based screening of the bacterial lysates}

All the bacterial lysates were screened for detection of target bacterial species (A. pleuropneumoniae, B. bronchiseptica, $H$. parasuis, $M$. hyopneumoniae and $P$. multocida) by PCR assay using specific oligonucleotides primers as mentioned in Table 1. PCR was performed in $25 \mu$ reaction volume containing Dream Taq ${ }^{\mathrm{TM}}$ Buffer $(10 \mathrm{X}), 2.5 \mu \mathrm{M}$ of each dNTPs, 20 pM of each specific primers, 1 Unit of Dream $\mathrm{Taq}^{\mathrm{TM}}$ DNA polymerase and $4.0 \mu \mathrm{l}$ of bacterial lysates. The reactions were performed with cyclic conditions as shown in Table 2.

\section{Isolation and identification of target bacteria}

All the samples found to be positive for target bacteria $(A$. pleuropneumoniae, B. bronchiseptica, $H$. parasuis, $M$. hyopneumoniae and $P$. multocida) by specific PCR assay were further processed for isolation of bacteria by standard bacteriological technique. After incubation, in each plate, based upon the colony characteristics, minimum 5 pure colonies were selected randomly and subjected to Gram's staining (Quinn et al., 1994). Each selected bacterial colonies were screened for identification up to species level by the BD Phoenix ${ }^{\mathrm{TM}}$ automated bacterial identification system as per the guidelines of the manufacturer. All the identified bacterial colonies were further subcultured on specific media for growth and further storage. The bacterial isolates were stored as a pure culture on semisolid agar at $4^{\circ} \mathrm{C}$ and also as glycerol stock (50\% glycerol in LB broth) at $-80^{\circ} \mathrm{C}$ for further use.

\section{Detection of specific virulence genes in the bacterial isolates PCR assay}

All the bacterial isolates were subjected to PCR assay for determination of selected virulence genes using specific oligonucleotide primers (Table 1). Bacterial lysates were prepared as mentioned earlier. PCR was performed in $25 \mu \mathrm{l}$ reaction volume containing Dream Taq $^{\text {TM }}$ Buffer (10X), 2.5 $\mu \mathrm{M}$ of each dNTPs, $20 \mathrm{pM}$ of each specific primers (Table 1), 1 Unit of Dream Taq ${ }^{\text {TM }}$ DNA polymerase and $4.0 \mu \mathrm{l}$ of bacterial lysates. The reactions were performed with cyclic conditions as shown in Table 2.

All the amplified products were analyzed by agarose gel electrophoresis (1.5\% agarose in 1XTAE) at $120 \mathrm{~V} / \mathrm{m}$ for 40 minutes and stained with ethidium bromide $(0.5 \mu \mathrm{g} /$ $\mathrm{ml})$. The products were visualized with a UV trans-illuminator and imaged with a gel documentation system (Alpha Imager, USA). A known molecular weight marker (100 bp DNA ladder) (BR Biochem, India) was also used for each run to compare the amplicon size.

\section{RESULTS AND DISCUSSION}

\section{Detection of bacterial pathogens by specific PCR assay}

By species specific PCR assay, a total of 110 samples were found to be positive for presence of selected bacterial pathogens, of which 20 (9.57\%), 1 (0.478\%), 86 (41.15\%), $2(0.956 \%), 1(0.478 \%)$ and $1(0.478 \%)$ were confirmed as A. pleuropneumoniae, B. bronchiseptica, $H$. parasuis, $M$. hyopneumoniae and $P$. multocida, respectively (Table 3 ).

\section{Isolation and identification bacterial pathogens}

Of the 110 PCR positive specimens, a total of 52 bacterial strains were isolated and identified by the standard bacteriological techniques and BD Phoenix ${ }^{\mathrm{TM}}$ automated bacterial identification system. A total of 11, 1, 39 and 1 bacterial isolates were identified as $A$. pleuropneumoniae, $B$. bronchiseptica, $H$. parasuis and $P$. multocida, respectively. M. hyopneumoniae could not be isolated (Table 3 ). 
Detection of specific virulence genes in the bacterial isolates PCR assay

A total of 6 A. pleuropneumoniae isolates were recorded as positive for $A p x I A$ and $A p x I I$ genes. In addition, $12 \mathrm{H}$. parasuis isolates were also recorded as positive for $v \operatorname{ta} A$ and cap $D$ genes. None of the other bacterial isolates were found to be positive for any other selected virulence genes.

Although pig husbandry is one of the major backbones of the rural economy of Mizoram, it used to suffer from several setbacks due to various diseases contributing a big hindering factor towards the steady growth of pig husbandry.
On many occasions, the piglets are being transported across the domestic and international borders due to shortage in supply of good quality piglets to the farmers for rearing. The present study was undertaken to find out the occurrence of porcine bacterial pathogens in the pigs migrated from Myanmar to the adjoining district Champhai in Mizoram.

$H$. parasuis was recovered in the highest number followed by $A$. pleuropneumoniae. Both the bacteria are considered to be the most commonly detectable normal flora of pig respiratory tract, which may develop clinical infestations under stress, particularly in immunocompromised conditions

Table 1: List of oligonucleotide primers used in the present study.

\begin{tabular}{|c|c|c|c|c|}
\hline Name of bacteria & Primer name & Primer sequence $\left(5^{\prime}-3^{\prime}\right)$ & d amplicon size (bp) & References \\
\hline \multicolumn{5}{|c|}{ Primers used for species specific detection of target bacteria } \\
\hline \multirow[t]{2}{*}{ A. pleuropneumoniae } & APXIVA- & F-TGGCACTGACGGTGATGA & 422 & Schaller et al. (2001) \\
\hline & 1 & R-GGCCATCGACTCAACCAT & & \\
\hline \multirow[t]{2}{*}{ B. bronchiseptica } & Fla2 & F-AGGCTCCCAAGAGAGAAAGGCTT & 237 & Hozbor et al. (1999) \\
\hline & Fla4 & R-TGGCGCCTGCCCTATC & & \\
\hline \multirow[t]{2}{*}{ H. parasuis } & $16 \mathrm{~S}$ & F-AGAGTTTGATCATGGCTCAGA & $1,391-1,394$ & Olvera et al. (2006) \\
\hline & & R-AGTCATGAATCATACCGTGGTA & & \\
\hline \multirow[t]{2}{*}{ M. hyopneumoniae } & $16 S$ & F-GAGCCTTCAAGCTTCACCAAGA & 649 & Kurth et al. (2002) \\
\hline & & R-TGTGTTAGTGACTTTTGCCACC & & \\
\hline \multirow[t]{2}{*}{ P. multocida } & KMT1T7 & F-ATCCGCTATTTACCCAGTGG & 460 & Townsend et al. (1998) \\
\hline & KMT1SP6 & R-GCTGTAAACGAACTCGCCAC & & \\
\hline & Primers & ed for determination of virulence genes of be & acterial isolates & \\
\hline \multirow[t]{6}{*}{ A. pleuropneumoniae } & apxIA & F-ATCGAAGTACATCGCTCGGA & 723 & Rossi et al. (2013) \\
\hline & & R-CGCTAAGCTACGACCGAAC & & \\
\hline & apxIB & F-TTATCGCACTACCGGCACTT & 811 & \\
\hline & & R-TGCAGTCACCGATTCCACTA & & \\
\hline & apxll & F-GAAGTATGGCGAGAAGAACG & 963 & \\
\hline & & R-CGTAACACCAGCAACGATTA & & \\
\hline \multirow[t]{6}{*}{ B. bronchiseptica } & bvgA & F-AATTTCGCAGCCATTCCTTTGAC & 768 & Kumar et al. (2014) \\
\hline & & R-GATCAGACTGCGGGGGTACAG & & \\
\hline & cyaA & F-GGTGCGAATCCGTTCAATCGACTA & 1185 & \\
\hline & & R-TTCCAGTACATCCGGCGAGGACTTC & & \\
\hline & flaA & F-CGCCGCCAACCAGTC & 736 & \\
\hline & & R-GTACGTACTGCCATGGCCCCG & & \\
\hline \multirow[t]{10}{*}{ H. parasuis } & vtaA & F-TTTAGGTAAAGATAAGCAAGGAAATCC & 460 & Lawrence and \\
\hline & & R-CCACACAАAАССТАССССТССТСС & & Bey (2015) \\
\hline & hhdBA & F-ATCTTGCCCTGATTAGAGAGTAGGAGT & & \\
\hline & & R-GTGAATATAGCCCTTATCCAAATAGGC & 557 & \\
\hline & fhuA & F-ATGGTTTGGTTGTAATGGAGTATC & 563 & \\
\hline & & R-AACAACGCCAGCTAGGCTTGTACT & & \\
\hline & IsgB & F-ATGAATTTGATTATTTGTATGACTCCATTT & 942 & \\
\hline & & R-CTATTGGCATGTGTAGTCAATTACTTC & & \\
\hline & capD & F-CGAAGGGAGTGTTTCTATCA & 958 & \\
\hline & & R-GAGTTTCTCACCAGGTCTAA & & \\
\hline \multirow[t]{6}{*}{ P. multocida } & ompH & F-CTGGTTTAGCGCTTGGTGTT & 242 & Rajkhowa et al., \\
\hline & & R-TCTACCCCAAGCTGCTTCAA & & $(2012)$ \\
\hline & ompA & F-AGCGCGTAGATTACAGACCA & 350 & \\
\hline & & R-GTGACCTGTTGCGCTGATAG & & \\
\hline & toxA & F-GGTAAAGAGTTTGCCGTGGA & 200 & \\
\hline & & R-CGAGGCTTTGTGAAAAGAGG & & \\
\hline
\end{tabular}


Transmission of Novel Bacterial Pathogens through Pigs Transported from Myanmar to Mizoram

Table 2: Thermal cycling conditions for the detection of various specific bacterial genes in the present study.

\begin{tabular}{|c|c|c|c|c|c|c|}
\hline $\begin{array}{l}\text { Name of the } \\
\text { target genes }\end{array}$ & $\begin{array}{c}\text { Initial } \\
\text { denaturation }\end{array}$ & Denaturation & Annealing & Elongation & $\begin{array}{c}\text { Final } \\
\text { extension }\end{array}$ & $\begin{array}{c}\text { Number of } \\
\text { cycles }\end{array}$ \\
\hline APXIVA-1 & $94 \mathrm{C} ; 5 \mathrm{~min}$ & $94 \mathrm{C} ; 30 \mathrm{sec}$ & $53 \mathrm{C} ; 30 \mathrm{sec}$ & $72 \mathrm{C} ; 30 \mathrm{sec}$ & $72 \mathrm{C} ; 4 \mathrm{~min}$ & 35 \\
\hline Fla2 and Fla4 & $94 \mathrm{C} ; 5 \mathrm{~min}$ & $94 \mathrm{C} ; 1 \mathrm{~min}$ & $60 \mathrm{c} ; 50 \mathrm{sec}$ & $72 \mathrm{C} ; 1 \mathrm{~min}$ & $72 \mathrm{C} ; 4 \mathrm{~min}$ & 35 \\
\hline H. parasuis(16S) & $94 \mathrm{C} ; 5 \mathrm{~min}$ & $94 \mathrm{C} ; 1 \mathrm{~min}$ & $55 \mathrm{C} ; 15 \mathrm{sec}$ & $72 \mathrm{C} ; 20 \mathrm{sec}$ & $72 \mathrm{C} ; 4 \mathrm{~min}$ & 30 \\
\hline M. hyopneumoniae (16S) & $94 \mathrm{C} ; 5 \mathrm{~min}$ & $94 \mathrm{C} ; 30 \mathrm{sec}$ & $60 \mathrm{C} ; 45 \mathrm{sec}$ & $72 \mathrm{C} ; 30 \mathrm{sec}$ & $72 \mathrm{C} ; 4 \mathrm{~min}$ & 35 \\
\hline KMT1T7 and KMT1SP6 & $94 \mathrm{C} ; 5 \mathrm{~min}$ & $94 \mathrm{C} ; 45 \mathrm{sec}$ & $56 \mathrm{C} ; 45 \mathrm{sec}$ & $72 \mathrm{C} ; 45 \mathrm{sec}$ & $72 \mathrm{C} ; 4$ min & 30 \\
\hline apxIA, apxIB and apxII & $94 \mathrm{C} ; 5 \mathrm{~min}$ & $94 \mathrm{C} ; 30 \mathrm{sec}$ & $60 \mathrm{c} ; 30 \mathrm{sec}$ & $72 \mathrm{C} ; 45 \mathrm{sec}$ & $72 \mathrm{C} ; 4 \mathrm{~min}$ & 35 \\
\hline bvgA, cyaA and flaA & $94 \mathrm{C} ; 5 \mathrm{~min}$ & $94 \mathrm{C} ; 50 \mathrm{sec}$ & $57 \mathrm{C} ; 60 \mathrm{sec}$ & $72 \mathrm{C} ; 90 \mathrm{sec}$ & $72 \mathrm{C} ; 4 \mathrm{~min}$ & 35 \\
\hline vtaA & $94 \mathrm{C} ; 5 \mathrm{~min}$ & $94 \mathrm{C} ; 45 \mathrm{sec}$ & $64 \mathrm{C} ; 45 \mathrm{sec}$ & $72 \mathrm{C} ; 60 \mathrm{sec}$ & $72 \mathrm{C} ; 4 \mathrm{~min}$ & 25 \\
\hline hhdBA, fhuA & $94 \mathrm{C} ; 3 \mathrm{~min}$ & $94 \mathrm{C} ; 30 \mathrm{sec}$ & $55 \mathrm{C} ; 60 \mathrm{sec}$ & $72 \mathrm{C} ; 90 \mathrm{sec}$ & $72 \mathrm{C} ; 4 \mathrm{~min}$ & 32 \\
\hline ompH,ompA andtoxA & $94 \mathrm{C} ; 5 \mathrm{~min}$ & $94 \mathrm{C} ; 30 \mathrm{sec}$ & $56 \mathrm{C} ; 45 \mathrm{sec}$ & $72 \mathrm{C} ; 45 \mathrm{sec}$ & $72 \mathrm{C} ; 4 \mathrm{~min}$ & 30 \\
\hline IsgB, capD & $94 \mathrm{C} ; 5 \mathrm{~min}$ & $94 \mathrm{C} ; 45 \mathrm{sec}$ & $56 \mathrm{C} ; 45 \mathrm{sec}$ & $72 \mathrm{C} ; 90 \mathrm{sec}$ & $72 \mathrm{C} ; 4 \mathrm{~min}$ & 30 \\
\hline
\end{tabular}

Table 3: Details of PCR based detection and bacteriological isolation and identification of various bacterial species in the specimens collected from pigs transported form Myanmar to Champhai district of Mizoram.

\begin{tabular}{lccc}
\hline Bacterial species & $\begin{array}{c}\text { Number of samples positive } \\
\text { for specific PCR }\end{array}$ & $\begin{array}{c}\text { Number of bacteria } \\
\text { isolated and identified }\end{array}$ & $\begin{array}{r}\text { Number of bacterial isolated } \\
\text { posses virulence gene (s) }\end{array}$ \\
\hline Actinobacillus pleuropneumoniae & 20 & 11 & 6 \\
Bordetella bronchiseptica & 1 & 1 & - \\
Haemophilus parasuis & 86 & 39 & 12 \\
Mycoplasma hyopneumoniae & 2 & 0 & - \\
Pasteurella multocida & 1 & 1 & - \\
Total & 110 & 52 & \\
\hline
\end{tabular}

(Galofré-Milà et al., 2017). The rate of isolation and identification of bacterial pathogens from any kind of hosts are dependent on various factors: sampling pattern, season, time of collection, treatment with antibacterial drugs, processing in the laboratories, media used, methods of identification and confirmation and so on. In an extensive epidemiological study conducted between 2013 and 2017, a total of 19673 bacterial strains were isolated from 44175 samples collected from 9661 pig farms that distributed in 16 Chinese major pig breeding provinces, where Streptococcus suis, H. parasuis, E. coli, P. multocida, A. pleuropneumoniae, B. bronchiseptica, S. enterica and Erysipelothrix rhusiopathiae were isolated at the rate of $16.9 \%, 9.7 \%, 6.3 \%, 3.4 \%, 0.3 \%, 1.5 \%, 2.3 \%$ and $0.9 \%$, respectively. Detection of $P$. multocida, B. bronchiseptica, $M$. hyopneumoniae and Salmonellaentericawere widely variable depending upon the geographical location and husbandry conditions (Zhang et al., 2019). In an earlier study, Varte et al. (2014) reported $3.15 \%$ of pig population of Mizoram as carrier of $P$. multocida of serogroup $A$ and $D$, although none of them were toxigenic strains and associated with progressive atrophic rhinitis. $P$. multocida and $B$. bronchiseptica are usually surviving simultaneously in the upper respiratory tract of pigs and associated with progressive atrophic rhinitis. Therefore, the detection of both the pathogens from the pigs of this region indicates the carrier status and may aggravate the condition with progressive atrophic rhinitis under favourable conditions.
The prevalence of $H$. parasuis in the nares has been linked to increased risk of infection by other pathogens. In contrary, Vahle et al., (1997) reported that detection of $H$. parasuis from the nasal cavity and tonsils do not provide a conclusive diagnosis for Glässer's disease in the animals, as the organisms are considered a commensal in the upper respiratory tract and both pathogenic and non-pathogenic strains can be isolated from these sites. Thus, $H$. parasuis present in nasal cavity or tonsils might not necessarily be the causal serovar for the disease (Olvera, 2006) and sampling the internal organs is recommended to determine the disease-causing serovar of $H$. parasuis. But the determination of such virulent organism from the healthy animals is always an indication of possible infection under immunocompromised conditions. So far, no published literatures could be traced on $H$. parasuis infestation in pigs in India, hence the present data could not be compared. In China, the incidence of $H$. parasuis in healthy and infected pigs are reported (Zhang et al., 2019), where $H$. parasuis isolation was more successful in weaner pigs (22.6\%, 192/ $849)$, followed by finisher pigs $(9.3 \%, 43 / 463)$ and sows (2.5\%, 9/363).

A. pleuropneumoniae, the causative agent of porcine contagious pleuropneumonia is worldwide in distribution. Acute disease, characterized by fibrino-hemorrhagic and necrotizing pleuropneumonia, is often fatal. Asymptomatic carriers of the bacterium, either those having survived acute disease or those that were subclinically infected, may harbor 
the organisms in nasal cavities, tonsillar crypts and chronic lung lesions, thus becoming a source of infection for naïve subpopulations (Klinkenberg et al., 2014). The estimation of the economic burden of this disease is mainly based on the occurrence of acute outbreaks characterized by high mortality, loss in production and high medical costs. Results from different studies about the impact of $A$. pleuropneumoniae infections on production parameters vary greatly. Few studies have confirmed the broadly accepted perception that average daily weight gain and feed conversion rates are negatively affected by the disease, mainly in pigs with chronic lung alterations (Hoflack et al., 2001). A reduction in daily weight gain by $33.6 \%$ and a decrease in feed efficiency ranging from $0.77 \%$ to $25.5 \%$ have been reported (Holmgren et al., 1999). The organism is reported from pigs of most of the countries (Sassu et al., 2018) but so far, no published data available from India. As there is no published data from India is available, we could not compare our data. This is probably the first report on the isolation and identification of $A$. pleuropneumoniae and $H$. parasuis from Indian pigs.

It is established that pigs illegally migrated from Myanmar to Mizoram are carrying various bacterial pathogens. In the present study, no attempt has been made to use any genotypic tool for comparison of genetic variations between the pathogens isolated from the native pigs of India and pigs migrated from Myanmar. The Mizoram state of India shares a porous international border of $510 \mathrm{~km}$ with Myanmar. Hundreds of pigs regularly enter into Mizoram through the international border illegally, not only for slaughtering but also for the breeding purpose (Rajkhowa et al., 2016). Two important bacterial pathogens, H. parasuis and $A$. pleuropneumoniae are not reported from any pig producing farm of India so far. Therefore, this may be considered as the first-ever report on isolation and identification of Haemophillus parasuis and Actinobacillus pleuropneumoniae in pigs in India and interestingly, both the organisms were isolated from pigs migrated from Myanmar to Mizoram.

\section{ACKNOWLEDGEMENT}

The authors are thankful to the DBT project on ADMac (DBTNER/LIVS/11/2012 dated 24/04/2014) and Institutional Biotech Hub (BT/04/NE/2009 Dated 21-09-2010) for providing all the facilities. They are also highly thankful to the Dean of the college for extending all the help in conducting the study.

\section{Conflict of interest}

The authors certify that there is no conflict of interest in publication of the article.

\section{Ethical statement}

Samples were collected from the clinically infected animals without any invasive techniques with the due permission of Institutional Animal Ethics Committee, CVSc and $\mathrm{AH}, \mathrm{CAU}$, Aizawl, Mizoram.

\section{REFERENCES}

Behera, S., Rana, R., Gupta, P.K., Kumar, D., Sonal, R.V., Arun, T.R. and Jena, D. (2018). Development of Real-Time PCR Assay for the Detection of Mycoplasmabovis. Tropical Animal Health and Production. 50: 875-882.

Das, A. and Bujarbaruah, K.M. (2005). Pig for meat production. Indian Journal of Animal Science. 75: 1448-1452.

Donko, T., Kovacs, M. and Magyar, T. (2003). The effect of atrophic rhinitis $(A R)$ on the weight gain of swine. Agriculturae Conspectus Scientificus. 68: 161-164.

Dutta, T.K., Roychoudhury, P. and Banik, S. (2009). Antimicrobial drug resistance of Pasteurella multocida isolated from pigs in NEH of India. Indian Journal of Animal Sciences. 79: 42-43.

Ferri, E.F.R., Gutierrez, C.B., de la Puente, V.A. et al. (2000). Bacterial meningitis in pigs: Glasser's disease. Porcine. 59: 43-60.

Galofré-Milà, N., Correa-Fiz, F., Lacouture, S., Gottschalk, M., Strutzberg-Minder, K., Bensaid, A., Pina-Pedrero, S. and Aragon, V., (2017). A robust PCR for the differentiation of potential virulent strains of Haemophilus parasuis. BMC Veterinary Research. 13: 124-129.

Hoflack, G., Maes, D., Mateusen, B., Verdonck, M. and de Kruif, A. (2001). Efficacy of tilmicosin phosphate (Pulmotil premix) in feed for the treatment of a clinical outbreak of Actinobacillus pleuropneumoniae infection in growing finishing pigs. Journal of Veterinary Medical Bulletin on Infectious Diseases and Veterinary Public Health. 48: 655-664.

Holmgren, N., Lundeheim, N. and Wallgren, P. (1999). Infections with Mycoplasma hyopneumoniae and Actinobacillus pleuropneumoniae in fattening pigs. Influence of piglet production systems and influence on production parameters. Journal of Veterinary Medical Bulletin on Infectious Diseases and Veterinary Public Health. 46: 535-544.

Hozbor, D., Fouque, F. and Guiso, N. (1999). Detection of Bordetella bronchiseptica by the polymerase chain reaction. Research in Microbiology. 150: 333-341.

Klinkenberg, D., Tobias, T.J., Bouma, A., van Leengoed, L.A.M.G. and Stegeman, J.A. (2014). Simulation study of the mechanisms underlying outbreaks of clinical disease caused by glycoprotein analysis of porcine bronchoalveolar lavage fluid reveals potential biomarkers corresponding to resistance to Actinobacillus pleuropneumoniae infection in finishing pigs. The Veterinary Journal. 202: 99-105.

Kumar, S., Singh, B.R., Bhardwaj, M. and Singh, V. (2014). Occurrence of Bordetella Infection in Pigs in Northern India. International Journal of Microbiology. doi: 10.1155/2014/238575. Epub 2014 Jan 12.

Kurth, K.T., Hsu, T., Snook, E.R., Thacker, E.L., Thacker, B.J. and Minion, F.C. (2002). Use of a Mycoplasma hyopneumoniae nested polymerase chain reaction test to determine the optimal sampling sites in swine. Journal of Veterinary Diagnostic Investigation. 14: 463-469.

Lawrence, P. and Bey, R. (2015). Map-based comparative genomic analysis of virulent Haemophilus parasuis serovars 4 and 5. Journal of Genomics. 3: 59-67.

Olvera, A., Cerdà-Cuéllar, M. and Aragon, V. (2006). Study of the population structure of Haemophilus parasuis by multilocus sequence typing. Microbiology. 152: 3683-3690. 
Quinn, P.J., Carter, M.E., Markey, B.K. and Carter, G.R. (1994). In: Clin. Vet. Microbiol., London, UK: Wolf Publishing; pp. 2166.

Rajkhowa, S., Shakuntala, I., Pegu, S.R., Das, R.K. and Das, A. (2012). Detection of Pasteurella multocida isolates from local pigs of India by polymerase chain reaction and their antibiogram. Tropical Animal Health and Production. 44: 1497-1503.

Rajkhowa, T.K., Mohanarao, G.J., Gogoi, A. and Hauhnar, L. (2016). Indian porcine reproductive and respiratory syndrome virus bears discontinuous deletion of 30 amino acids in nonstructural protein 2. Virus Diseases. 27: 287-293.

Rossi, C.C., Guimaratilde, W.V., de Queiroz, M.V. and Bazzolli, D.M.S. (2013). Face to face with Actinobacillus pleuropneumoniae: landscape of the distribution of clinical isolates in southeastern Brazil. African Journakl of Microbiology Research. 7: 2916-2924.

Sassu, E.L., Bossé, J.T., Tobias, T.J., Gottschalk, M., Langford, P.R. and Hennig-Pauka, I. (2018). Update on Actinobacillus pleuropneumoniae-knowledge, gaps and challenges. Transboundary and Emerging Diseaes. 65 Suppl1: 72-90.

Schaller, A., Djordjevic, S.P., Eamens, G.J., Forbes, W.A., Kuhn, R., Kuhnert, P., Gottschalk, M., Nicolet, J. and Frey, J. (2001). Identification and detection of Actinobacillus pleuropneumoniae by PCR based on the gene apxIVA. Veterinary Microbiology. 79: 47-62.

Thacker, E. and Minion, F. (2012). Mycoplasmosis. In: Zimmerman, J.J., Ramirez, A., Schwartz, K.J. and Stevenson, G.W. (eds.). Diseases of Swine, $10^{\text {th }}$ edn. Ames: Wiley-Blackwell Publishing, pp. 779-798.
Townsend, K.M., O’Boyle, D., Phan, T.T., Hanh, T.X., Wijewardana, T.G., Wilkie, I. and Frost, A.J. (1998). Acute septicaemic pasteurellosis in Vietnamese pigs. Veterinary Microbiology. 63: 205-215.

Vahle, J.L., Haynes, J.S. and Andrews, J.J. (1997). Interaction of Haemophilus parasuis with nasal and tracheal mucosa following intranasal inoculation of cesarean derived colostrum deprived (CDCD) swine. Canadian Journal of Veterinary Research. 61: 200-206.

Varte, Z., Dutta, T.K., Roychoudhury, P., Begum, J. and Chandra, R. (2014). Isolation, identification, characterization and antibiogram of Pasteurella multocida isolated from pigs in Mizoram with special reference to progressive atrophic rhinitis, Veterinary World. 7: 95-99.

Zhang, P., Chaoyang, Z., Virginia, A., Xue, Z., Ming, Z., Congming, W. and Zhangqi, S. (2019). Investigation of Haemophilus parasuis from healthy pigs in China. Veterinary Microbiology. DOI: https://doi.org/10.1016/j.vetmic.2019.02.034.

Zohilmpuia, Roychoudhury, P., Subudhi, P.K., Dutta, T.K., Behera, P.S. and Kalita, G. (2018). Molecular detection and characterization of Orf5 Gene of Porcine Reproductive and respiratory Syndrome Virus from outbreaks in Mizoram. Indian Journal of Comparative Microbiology, Immunology and Infectious Diseases. 39: 102-105. 